\title{
MULTI-ENERGY COUPLING SYSTEM BASED ON PLC AND WINCC
}

\author{
Yang Huizhen ${ }^{1}$, Cai Yingling ${ }^{2}$, Xu Hui ${ }^{3}$ \\ ${ }^{1}$ College of Mechanical Engineering, Shanghai University of Engineering Science, Shanghai 201620, China \\ ${ }^{2}$ College of Mechanical Engineering, Shanghai University of Engineering Science, Shanghai 201620, China \\ ${ }^{3}$ College of Mechanical Engineering, Shanghai University of Engineering Science, Shanghai201620, China
}

\begin{abstract}
The development and utilization of multi-energy coupling platform has been completed by the software of Siemens S7-200 and configuration software WinCC. PLC of Siemens is used to collect temperature, flow rate, quantity of heat, power, etc. and calculate the COP of heat pump and the system. The detecting system is composed of the slave computer PLC and the host computer WinCC. The real-time monitoring and control function are realizedbythis system.And six operational modes of the solar-ground source heat pump system are designedaccording to different external conditions, which is an effective way to make up the shortcomings of the solar energy and GSHP (Ground Source Heat Pump) individually.
\end{abstract}

Key words: PLC, WinCC, Monitoring system, Operational mode

\section{INTRODUCTION}

With the over-exploitation of coal and other traditional energy sources, the environmental problems which represented by "haze" and water pollution is deteriorating. The government report released in 2014 emphasizes the "Heavyweight Thunder Governance Haze" for the first time, and clears to foster some emerging industries such as new energy development ${ }^{[1,2]}$. As the second to the solar cleans energy geothermal energy may usher in a new development opportunity following the solar energy, and the investment potential of the future will be expected to release. However, equilibrize the system load in the whole year is the mainly bottlenecks in the development of ground heat pump, in other words, there is a problem in the restoration of the ground temperature. As one of the cleanest energy, solar energy is also an inexhaustible source. However, the characteristics of solar energy such as intermittent, instability, low energy flux density, etc. lead to instability of the solar thermal system. Hence, combined solar energy and geothermal energy not only increases the performance of coupling system very well, but also overcome the shortcoming of using solar energy or geothermal energy alone. The application of solar energy and geothermal energy in buildings is attracting the attention of people more often. ${ }^{[3-5]}$.

\section{EXPERIMENT PLATFORM}

The solar-ground heat pump system experiment platform mainly includes vertical U-tube ground heat exchanger, heat pump, evacuated tubular collector and the terminal unit of air-conditioning system. The terminal unit of air-conditioning system is composed of fan coil, floor radiant heating system and capillary tube radiation heating system. This system schematic is shown in Fig.1. Thermal parameters and equipment running status in this system are monitored by the host computer monitoring platform. Thermal parameters tested in this system are temperature, flux, quantity of heat, power, etc. 


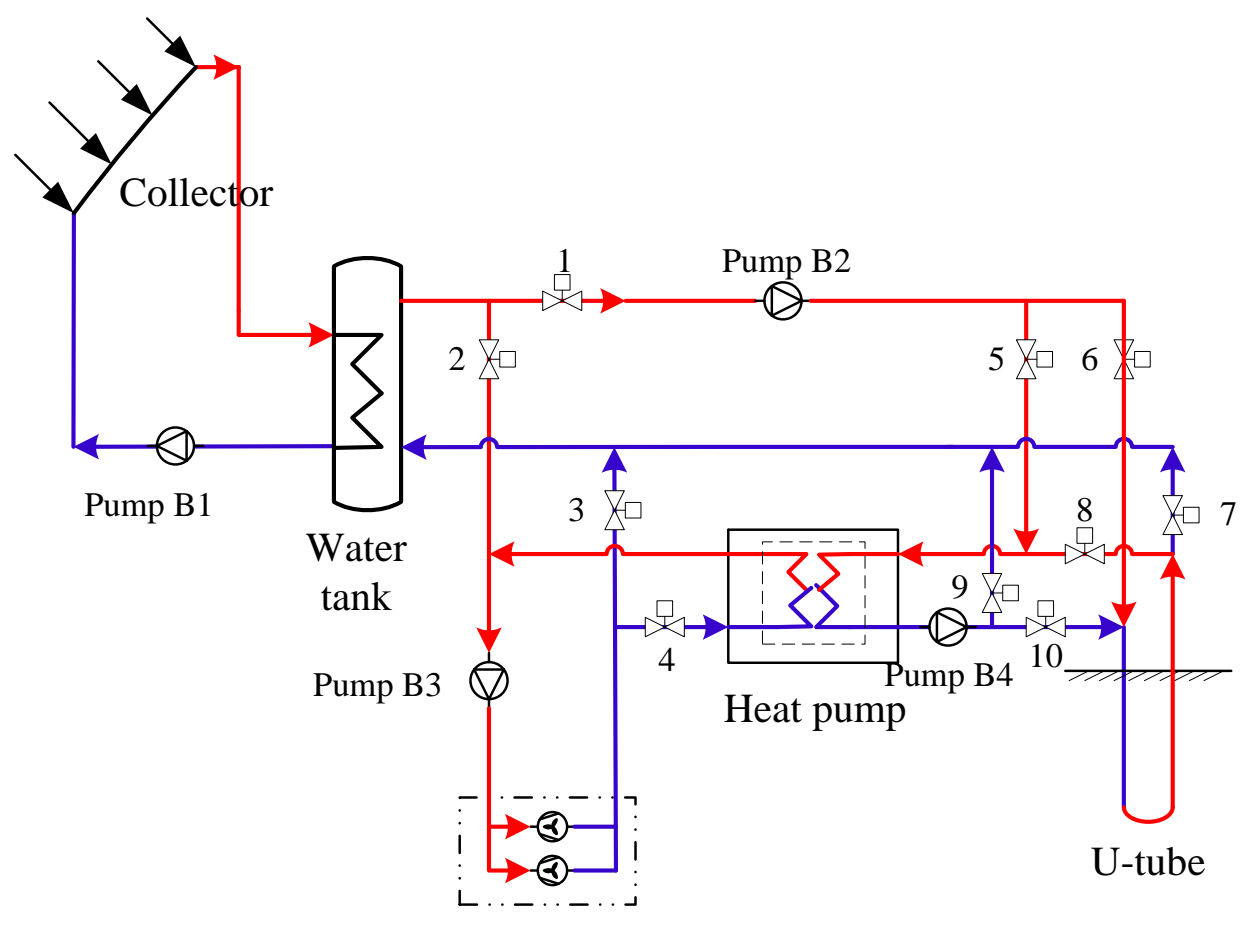

Air conditioning terminal

Fig-1: Schematic diagram of solar-ground heat pump system

\subsection{The Solar-Collector System}

Solar radiation intensity and Daily solar radiation are measured by solar radiation measurement instrument. The pyranometer TBQ-2-B-I is adopted in this system. The measurement instrument for this system is FU-100 automatic measuring instrument which used for test the daily solar radiation by RS-232 interface. Evacuated tubular collectors are mainly applied in SAGSHP. It's used to heat the water in the storage tank. The circulation pump of solar-collector will be started when the maximum temperature difference between the export temperature of solar-collector and the average temperature of the storage tank is larger than $8^{\circ} \mathrm{C}$; The circulation pump of solar-collector will be stopped when the minimum temperature difference is smaller than $3^{\circ} \mathrm{C}$. There is a temperature sensor with transmitter in the import and export of the solar-collector. There is also a temperature sensor in the import and export of the storage tank. The material of the platinum thermistor sensor is Pt100, and the output signal is 4 20mA current signal, which pass the analog quantity on PLC.

\subsection{The Heat Pump And Ground Heat Exchanger}

\section{(GHE)}

The heat pump in this system is provided by an Air
Conditioning Equipment Co., Ltd. in Shanghai,and the type of heat pump is MSR-J052WHC. The heat pump consists of a closed refrigerating circuit, which includes compressor, four-way reversing valve, thermal expansion valve and casing coaxial heat exchanger. Rated refrigerating capacity and rated heating capacity respectively is $12.6 \mathrm{KW}$ and $16.5 \mathrm{KW}$, respectively. Water flux of the source side and user-side is $2.4 \mathrm{~m}^{3} / \mathrm{h}$ and $1.94 \mathrm{~m}^{3} / \mathrm{h}$, respectively.

The Ground Heat Exchanger (GHE) in this system is vertical U-tube ground heat exchanger, which consists of two $30 \mathrm{~m}$ deep boreholes, five $60 \mathrm{~m}$ deep boreholes and three $90 \mathrm{~m}$ deep boreholes.K-type thermocouples (in depth direction) are set every $15 \mathrm{~m}$. The borehole diameter is $110 \mathrm{~mm}$ and spacing ofboreholesis $4.5 \mathrm{~m}$. One type of high-density polyethylene(HDPE) pipe named SDR11 is selected as the material of the Vertical U-tube ground heat exchanger according to $\langle$ Technical code for ground-source heat pump system》(2009) ${ }^{[6]}$.

\subsection{Circulating Pump}

The circulating pumps in this system are the circulation pump of solar-collector, circulation pump of solar heaters, terminal circulation pump and circulation pump of GHE. The last two 
pumps are variable frequency pumps with transducers which aimed to control and adjust the flow rate conveniently, and to optimize the system efficiency.

\section{THE BRIEF INTRODUCTION OF THE SYSTEM}

A widely applied distributed control system is adopted in this system. Concentrative monitor and separate control is the distinctive characteristics of this control method, and itconsists ofthe host computer monitoring system and field equipment. As the host computer of the monitoring system, the configuration software WinCC not only complete the configuration of surveillance and control but also real-time display the dynamic data in the interface and realize the function ofalarming, data archiving and exporting, on-line reports, display dynamic tendency of different parameters, etc..The slave computer of the monitoring system consistofPLC-200 andintelligent flow cruise instrument, intelligent electric meters, temperature sensors, pressure sensors, etc.The slave computer of the monitoring system is used to complete the function that collect date and automatic control and switch the operational mode.Thestructural component is presented in Fig.2.

\section{MONITORINGSYSTEM[7]}

\subsection{The Hardware of the System}

The solar-ground heat pump system has thirty-eightdigital input (DI) signal, twenty-eightdigital output (DO) signal, twelve signals of Pt100 temperature sensors, six analog quantity input signal of standard current orvoltage and two analog quantity output signal. According to control requirements and the terminal number, atype of DCS7-200 CPU226 (24DI/14DO) is selected in this system which has six extension modules in total. These six extension modules consist of one digital quantity extension module of EM223 (16DI/16DO), one analog quantity extension module of EM231 (8AI), one analog output extension module of EM232 (4AO) and three thermal resistance extension module of EM231rtd (4AI). The module of PLC communicates with fieldbus through communication protocol of MODBUS, and the date collected from the field will be transferred to PLC, then the computer will connect with the slave computer PLC by the method of PPI/PC Cable (PPI) communication protocol to achieve the real-time data transfer, the trapezoidal chart program of the system can be carry on in STEP 7-Micro/Win V4.0 finally.

\section{THE SLAVE COMPUTER OF THE}

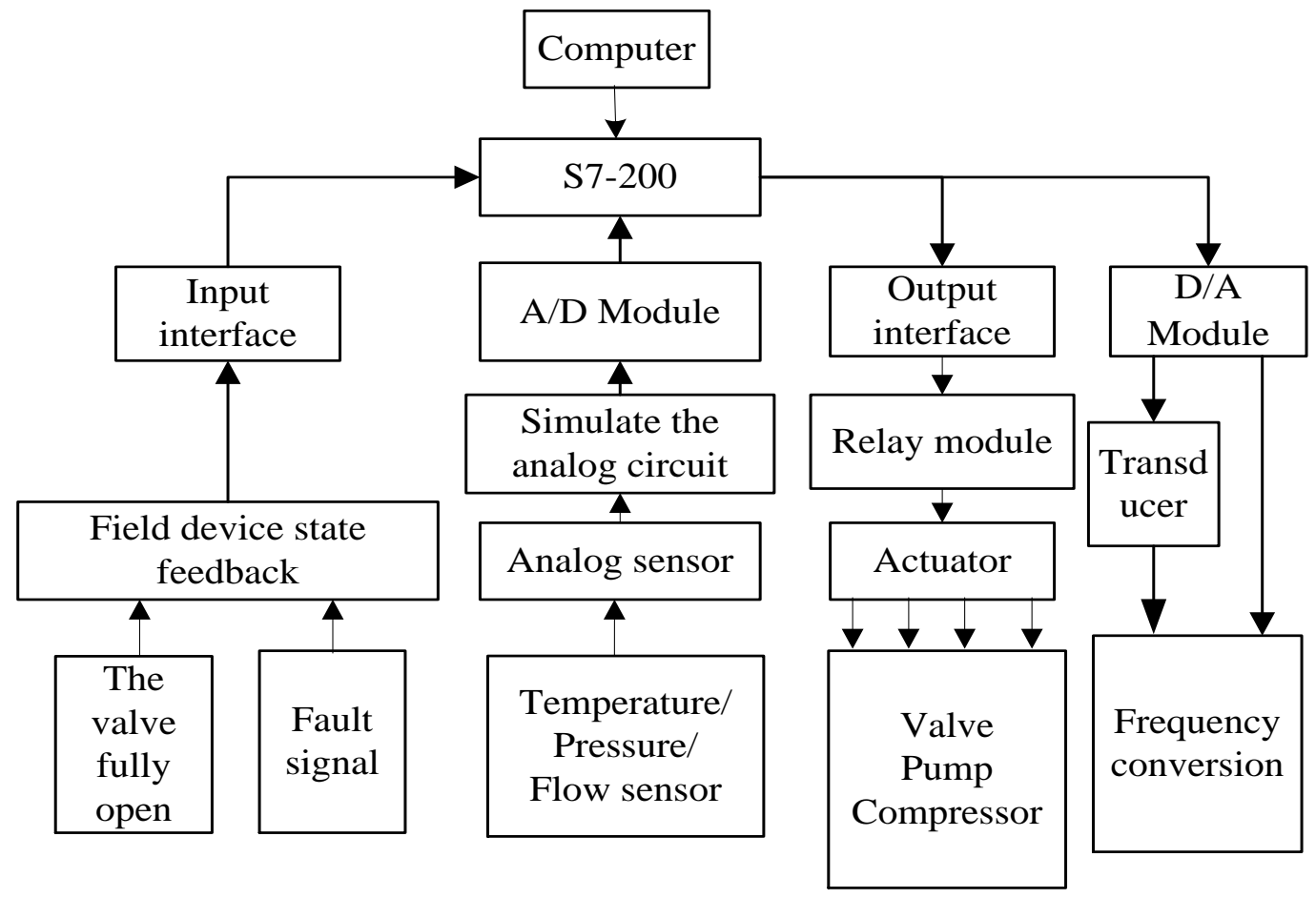

Fig-2: Schematic Diagram Of Structural Components 


\subsection{The Operating Principle of the System}

The instruments measure each control points, output 4 20mA signals of each control points, and then turn the signals into digital through the simulation of transducing circuit and A/D conversion modules and transfer them to the computer. The feedback information about the fieldbus equipment operating status will input PLC, then conductthe D/A conversion and execute corresponding action. The system can be switched automatic mode and manual mode when the system running. The manual mode is very simple and reliable and makes users more convenience to handle it. Most important of all,the manual mode can commissionand operate all parts of the whole system before the automatic mode is turned on. The automatic mode can largelysave labor, reduce unnecessary mistakes in the process of artificial operation and realize unattended monitoring system.

\section{THE ADMINISTRATIVE MONITORING} SOFTWARE OF THE HOST COMPUTER

The administrative monitoring software of the host computer (human-machine interface(HMI)) adopted in this system is developed by configuration software SIMATIC WinCC 7.0of Siemens which adopts standard Microsoft SQL Server 2000 database to archive dates, has the function of Web Browser, and remote monitoring real-time dynamic picture to adjust the system at any time. The software also can communicate with the slave computer PLC through OPC (OLE for Process
Control) to display the date on HMI directly. System regulation interface includes mode selection, the operation status of every mode, field data, the import and exporttemperaturetrend chart of the heat medium,etc.Its main features are as follows:

1) The main menu in the HMI includes maininterface and flow chart of the whole system, six operational mode switch button of the solar-ground heat pump system,switch button formanual mode.

2) The flow chart and parameter display interface are mainly used to real-timeand dynamic reflect the operation status of the system.

3) The trend chart and date archiving are mainly used to plot real-time curves of temperature, and then archive the real-time date into EXCEL. It's very convenient to process data in the EXCEL in the future.

4) The alarming function canalarm and record them when parametersover standard, then you can check out detailed historical records, alarming location, and alarming reasons in the alarming report that has been archived before.

Thewhole interface isshown in Fig.3, and the interface is designed in four modules that are the monitoring module, the fault alert module, the date recoding module and the report generation module. 


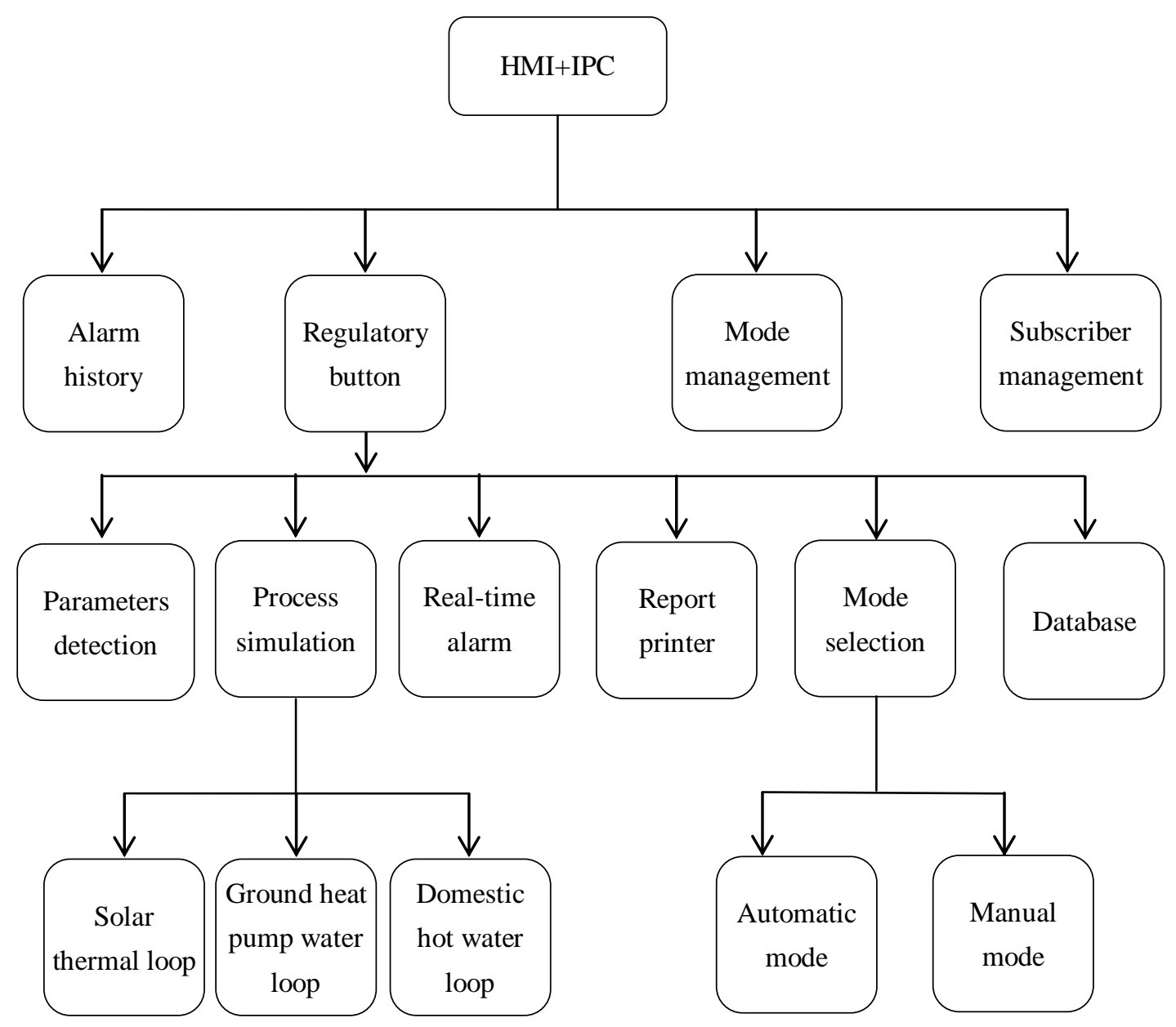

Fig-3: The structure chart ofmonitoring system

\section{ANALYZE THE OPERATIONAL MODE OF THE}

\section{SYSTEM}

The instability ofenergy supplyin the solar energy utilization is one of the main obstacles to the popularization of solar buildings. At the same time, solar energy can be vulnerable to outsideinterference. The effective solar irradiation in different climate is very different.Hence, this article has design six operational modes according to differentenvironmentalconditions that include heating directly by solar energy heat-collecting system, heating by solar heat pump system, heating by GSHP, heating by solar-ground heat pump system,alternate heating by solar heat pump system and GSHP, andstorageheat into ground with buried pipes. According to the designing of above modes, the coupling heating system can operate normally during the heating period.

Mode 1: heating directly by solar energy heat-collecting system

This mode will be selected when outlet temperature in the load side of the hot water tank is higher than the designed temperature. It's unnecessary to start the heat pumpand auxiliary heat source. It will be started when you turn on valve2, valve3, pump1, pump3 and turn off other valves and pumps.

Mode 2: heating by solar heat pump system

This mode will be selected when outlet temperature in the load side of the hot water tank is lower than the designed temperature, but higher than the inlet temperature in the source side of the heat pump.It will be started when you turn on valve1, 4, 5 and 9, andpump B1, B2, and B3.

Mode 3: heating by ground source heat pump system This mode will be selected when outlet temperature in the load side of the hot water tank is lower than the inlet temperature in the source side of the heat pump. The solarcollector cannot work and will be turn off. Then this mode will be started when you turn on valve3, 8 and 10, andpump B3, and B4. 
Mode 4: heating by solar-ground heat pump system

This mode will be selected when the outlet temperature in the load side of the hot water storage tank is higher than the inlet temperature in the source side of the heat pump, but the heat offered by solar heat pump system cannot meet the need of the entire heating load. It will be started when you turn on valve1, 4, $6,7,8$ and 10 , and all of the pumps.

Mode 5: alternate heating by solar heat pump system and ground source heat pump system

This modewill be selected when the quantity of heat provided by solar collecting systemonlysatisfy the user demand at a specific period of time; at the last part of timethe heating will be providedbyground source heat pump system. This mode will be started when you turn on valve1, 2, 3, 4, 6, 7, 8 and 10, and all of the pumps.

Mode 6: storage heat into ground with buried pipes

This modewill be selected whenthe heating load is small during the initial and finalheating season. The extra heatis provided by the solar collecting system will flow into buried pipes and transfer heat with surrounding ground, and recover the decline of groundtemperature due to long-term to provide heating for buildings. This mode will be started when you turn on valve1, 6 , and 7 , and pump B1, and B3.

\section{ANALYZE THE DATE OF SOLAR-GROUND}

\section{HEAT PUMP SYSTEM[8,9]}

In the testing procedure of solar-ground pump system, the frequency of variable frequency pumpis setto $50 \mathrm{HZ}$. The daily solar irradiationwill be recordedduring the experiment,and thermal parameters also will be collectedby the slave computer PLC200 in order to offer dates to analyze the performance of the solar-ground pump system. Calculated the solar collectorheat gain and the efficiency of the solar collecting system according to formula (1) and (2), and calculated the COP of the solar independent heating system according to formula (6).

$\mathrm{Q}_{\mathrm{jj}}=4.19 \mathrm{G}_{\mathrm{j}}\left(\mathrm{T}_{\mathrm{jj}}-\mathrm{T}_{\mathrm{jc}}\right)$
Here : $\mathrm{Q}_{\mathrm{jj}}$ - solar collectorheat gain, $\mathrm{kW}$

$\mathrm{G}_{\mathrm{j}}$ - the flux of heating medium in solar collecting system, $\mathrm{kg} / \mathrm{s}$

$\mathrm{T}_{\mathrm{jj}}$ - inlet temperature of solar collector, ${ }^{\circ} \mathrm{C}$

$\mathrm{T}_{\mathrm{jc}}$ - outlet temperature of solar collector, ${ }^{\circ} \mathrm{C}$

$\eta=\frac{\sum Q_{j j}}{A H}$

Here : $\eta$-efficiency of the solar collecting system $\sum \mathrm{Q}_{\mathrm{jj}}$ - total heat gain of the solar collector, $\mathrm{kW}$

A -insolation area of the solar collector, $\mathrm{m}^{2}$

$\mathrm{H}$-solar irradiation of the lighting surface, $\mathrm{MJ} / \mathrm{m}^{2}$

$\mathrm{Q}_{\mathrm{tj}}=4.19 \mathrm{G}_{\mathrm{j}}\left(\mathrm{T}_{\mathrm{jj}}-\mathrm{T}_{\mathrm{jC}}\right)$

Here $: \mathrm{Q}_{\mathrm{tj}}$ - heat transfer of tank in the solar collector side, $\mathrm{kW}$ $\mathrm{G}_{\mathrm{j}}$ - flux of heating medium in the solar collector side, $\mathrm{kg} / \mathrm{s}$ $\mathrm{T}_{\mathrm{jj}}$-inlet temperature of tank in the solar collector side, ${ }^{\circ} \mathrm{C}$ $\mathrm{T}_{\mathrm{jC}}$ - outlet temperature of tank in the solar collector side, ${ }^{\circ} \mathrm{C}$ $\mathrm{Q}_{\text {th }}=4.19 \mathrm{G}_{\text {th }}\left(\mathrm{T}_{\text {thc }}-\mathrm{T}_{\text {thj }}\right)$

Here : $Q_{t h}$ - heat transfer of tank in the heating side, $\mathrm{kW}$ $\mathrm{G}_{\mathrm{th}}$ - water flux in the heating side, $\mathrm{kg} / \mathrm{s}$

$\mathrm{T}_{\text {thc }}$ - outlet temperature of tank in the heating side, ${ }^{\circ} \mathrm{C}$ $\mathrm{T}_{\text {thj }}$ - inlet temperature of tank in the heating side, ${ }^{\circ} \mathrm{C}$

Ground source heat pump system operates alone may sharply increase the extraction of heat from ground, accelerate the temperature of ground decline, and destroy the underground temperature field which cause the efficiency of the GSHP dramatically decline in the coldest month of winter. In this case, we can select to add the auxiliary heating source which can have the effect of peak clipping and alleviate the decline of the ground temperature at a certain extent to ensure the system operates efficiently. Fig.4 shows the underground temperature tendency in mode 4 during February 16, 2015 a.m. 8:00 February 18, a.m. 7:00, and Fig.5 shows the variation tendency of solar irradiation, outlet temperature of solar collector, and inlet temperature of evaporator in this period of time. 


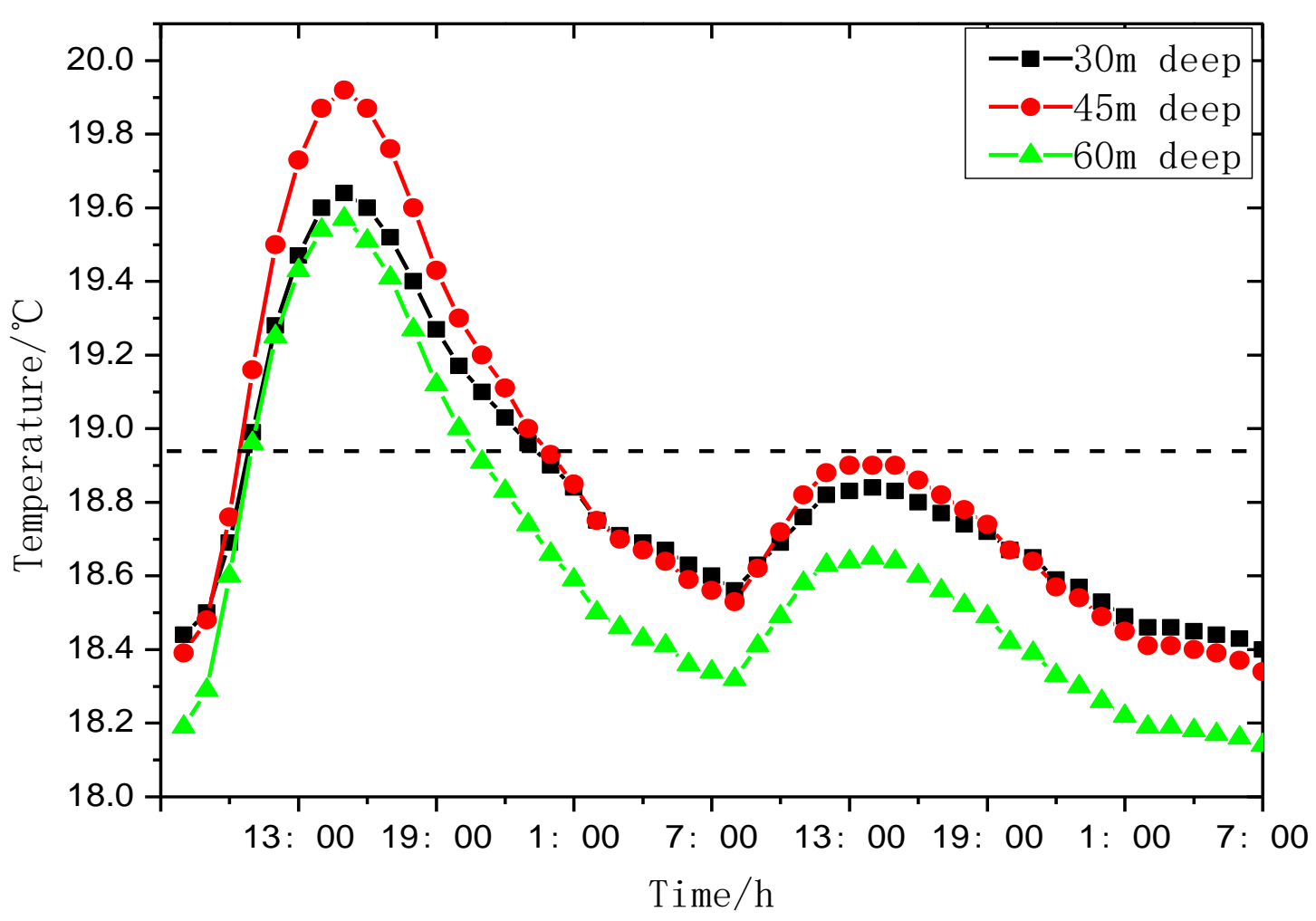

Fig-4: Ground temperature in the test of mode 4

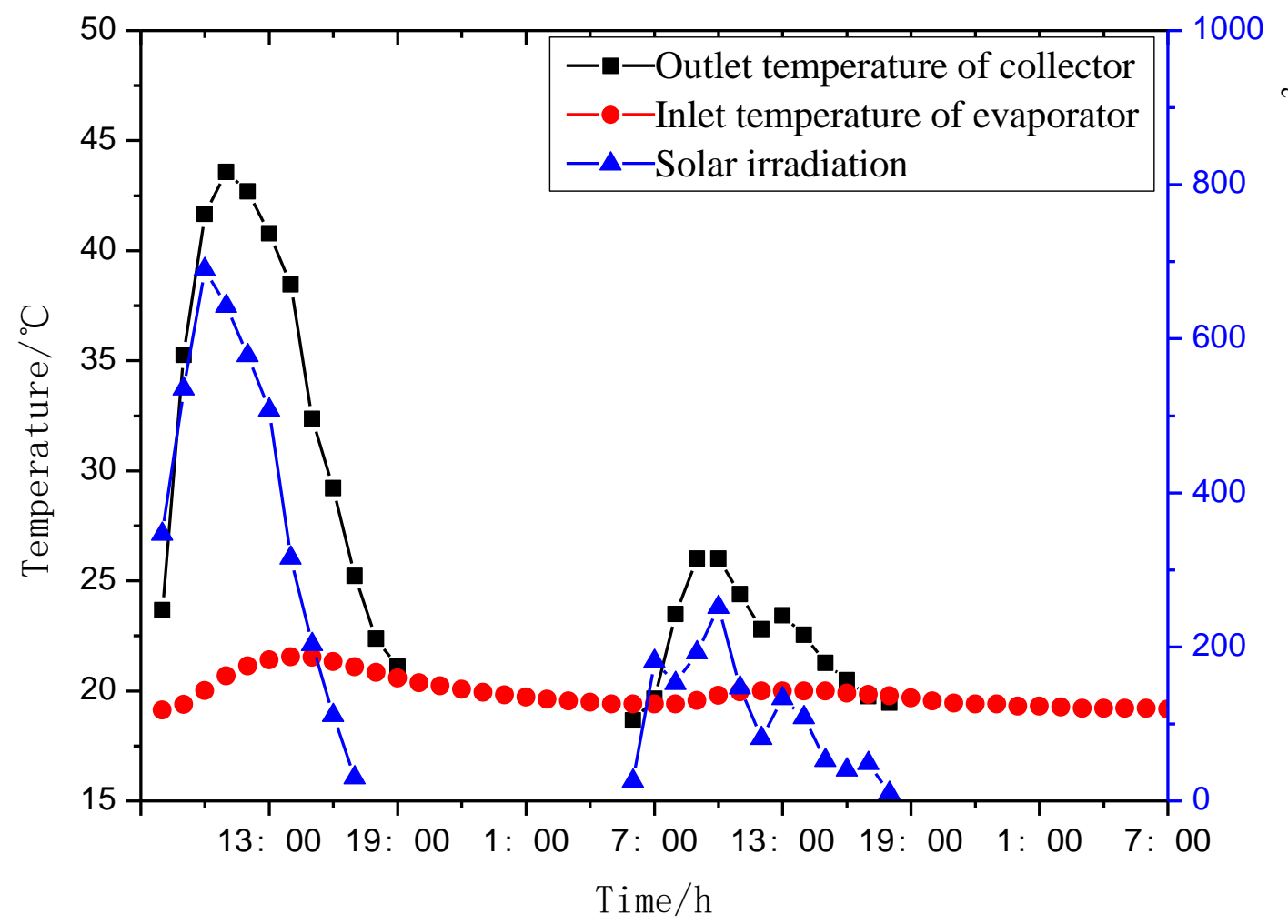

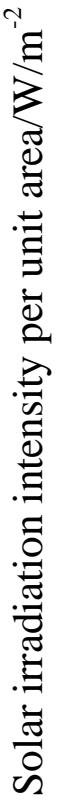

Fig -5: Theoutlet temperatureof collector, inlet temperature ofevaporator and the solar irradiationin the test of mode 4 
It can be seen from the above two pictures, before 9:00, the solar irradiation is poor and the heat pump mainly absorb heat from the ground. Although the amount of solar irradiation is poor, there is still a part of the heating that can be transmitted to the ground through hot water tank, so the ground temperature presents a slow increase trend. After 9:00, as the intensity of the solar irradiation gradually strengthen, outlet temperature of the solar collector reaches maximum temperature $43.58^{\circ} \mathrm{C}$ and the buried pipes will release heat to the ground around it because the temperature of the buried pipes is higher than the ground temperature at this moment. The buried pipes were converted into heat absorption until 23:00 due to the effect of hot water tank. Compare to the mode that heating by solar heat pump system, the inlet temperature of evaporator just presents a gently rising trend even if the temperature of water in the tank rise sharply due the solar-ground heat pump system takes ground as a huge buffer which ensure the system run more security and stability. The buried pipes may absorb heat from the ground in the overcast day because the solar irradiation is too poor to offer enough heat to the heating load. In conclusion, the operation of solar-ground heat pump is a dynamic coupling process of absorb and release heat in sunny day.

\section{CONCLUSIONS}

As an auxiliary heat source, solar energy combined with ground heat pump provide buildings with the required heat, which can achieve the combined heating in the system of solar-ground heat pump. In this system, the status-switch of different modes relatively intelligently implement the function of the automatic control system based on external conditions, and can be viewed as the control point according to the outlet temperature of the storage tank.

(1) According to the requirement of solar-ground heat pump, combined with the demand of different operation modes under different conditions and based on configuration software, the monitoring interface of the system has been designed.And the monitoring interface of the system has been designed based on configuration software, which can provide operation conditions for users straightforwardly.

(2) The intelligent system has been designed through the programmable control technology, frequency conversion technology and sensor technology, and realized the status-switch of different modes of solar-ground heat pump system.

(3) Typically, in winter, the intelligent detection and control of solar-ground heat pump system is achieved by this system, and the related basic data is obtained. Hence, solar-ground heat pump system is a dynamic coupling process of heat absorption and release.

\section{ACKNOWLEDGEMENT}

This project is sponsored by Shanghai University of Engineering Science Innovation Fund for Graduate Students (No.E1-0903-14-01020)

\section{REFERENCES}

[1].Beijing Municipal Bureau of Statics, 2013. Beijing Statistical Yearbook 2013.China Statistics Press, Beijing, China (in Chinese).

[2].China National Environmental Monitoring Centre, 2014. Daily Report of Air Quality.www.cnemc.cn (in Chinese accessed 10.06.14.)

[3].Weibo Yang, Lulu Sun, Yongping Chen, Experimental investigations of the performance of a solar-ground source heat pump system operated in heating modes [J].Energy and Buildings, 2015,89(1):97-111.

[4].Dai L, Li S, Duanmu L, et al. Experimental performance analysis of a solar assisted ground source heat pump system under different heating operation modes[J]. Applied Thermal Engineering. 2015, 75(1): 325-333.

[5].Zhu N, Hu P, Xu L, et al. Recent research and applications of ground source heat pump integrated with thermal energy storage systems: A review[J]. Applied Thermal Engineering. 2014, 71(1): 142-151.

[6].Qinyu Zhu, Wei Xu, Liang Shen. 《Technical code for ground-source heat pump system》 (2009) [J].Construction Technology.2009,4.

[7].KeningXie,Luyi Xia. "The principles of PLC and programming".Electronic industry press.2002.8.

[8].Simulationand Experimental Verification of Vertical Ground-coupled Heat PumpSystems (Closed Loop)[M].

[9].Smetana, Frederick O., 1928-.Results of heating mode performance tests of a solar-assisted heat pump[M].Washington, D.C. : National Aeronautics and Space Administration, Scientific and Technical Informati.1979. 


\section{BIOGRAPHIES}

\section{Corresponding Author:}

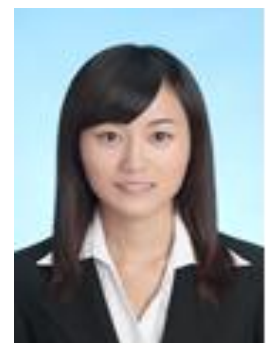

YangHuizhen, Female, Master Of

Engineering, Research Direction For

Renewable Energy Application In

Buildings.

E-mail: 572869789@qq.com 